DOI: 10.4081/aina.2021.4.499

\title{
Varicocele and varicocelectomy: Which news from the past?
}

\begin{abstract}
Nicola Zampieri
Woman \& Child Hospital, Department of Surgery, Dentistry, Paediatrics and Gynecology; Division of Pediatric Surgery, University of Verona, Italy.
\end{abstract}

KEY WORDS: Varicocele; Treatment; Option; Fertility.

Submitted 12 October 2021; Accepted 12 October 2021

To the Editor,

In 1952, after many centuries, the varicocele was treated to resolve infertility.

From Celsus to modern surgical techniques, over the centuries, many surgeons have proposed numerous treatment options, some very traumatic others more "physiological" (1-14).

Cases of varicocele have been treated because they were associated with "melancholic blood" or were associated with pain or were associated with infertility. However, since the latest clinical research, varicoceles have been treated mainly because they are associated with infertility, although recently the treatment of varicoceles, in the era of medical assisted procreation, has been questioned (15-17).

Therefore, there are some fundamental points to clarify. Why do patients with varicoceles become infertile? Patients with subclinical varicoceles are now surgically treated if there is alteration of the semen, why do we have to operate a patient with varicocele if we can use assisted reproduction?

A fundamental point is to clarify the role of varicocelectomy on the pregnancy rate; does it make sense to perform expensive (robotic varicocelectomy), or potentially harmful (x-ray embolization) surgical treatments if we then have to resort to assisted reproduction? What treatment can we offer to adolescents or what therapeutic procedure should we do for adolescents?

Finally, are we therefore returning to treat varicocele only if associated with pain, because for infertility we will have assisted reproduction?

With respect to the history of surgical procedures proposed to treat varicocele, "innovative" were Osborn and Ogston who, between 1880 and 1886, proposed a trans-scrotal treatment using a hairpin (without closing the artery) and a glowing needle. Was this perhaps the first "bipolar cautery" varicocelectomy? $(9,13)$

However, it is interesting to note that from the earliest treatment in history, Corner, Skillen, O'Conor, and Robson reported numerous complications and raised doubts on the real benefit of the procedure $(4-6,11)$.

Tait in 1904 was the first to introduce clear guidelines about clinical indications for varicocelectomy: one should operate large varicocele (or painful varicocele) including cases with testicular atrophy or marked endo-phlebitis and varicocele causing the rejection of candidates for certain positions (Army and Navy). In his "guidelines" he also added more information about who should be treated: voluminous and painful varicocele equivalent to an appreciable deformity and smaller varicocele at the patient's repeated request to be rid on an infirmity.

Finally, he added a last important chapter: one should never operate varicocele in genitourinary hypochondriacs or in neurasthenics and in case of simple dilatation of the veins inducing no symptoms (the most common form of varicocele) (7).

In comparison to the, more or less invasive, treatments proposed from Celsus onwards, to the surgical indications proposed in the past, to the results of the first cases treated in history and to the related post-operative complications, what have we learned or modified with respect to the past?

Perhaps the only answer we can give is that we still know very little about varicocele and its treatment.

\section{REFERENCES}

1. Marmar JL. The evolution and refinements of varicocele surgery. Asian J Androl 2016; 18:171-8.

2. Coutts WE. Orchidopexy for varicocele. A method for treating varicocele by means of living tissue. Ann Surg. 1928; 88:1093-5.

3. Porrit AE. The injection treatment of hydrocele, varicocele, burse and nevy. Proc R Soc Med 1931; 24: 971-975.

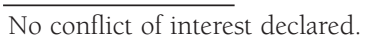


4. O'Connor J. The radical cure of varicocele. Br Med J. 1921; 1:783-789.

5. Skillen PG. A consideration of the varicocele operation and avoidance of post-operative induration. Ann Surg. 1920; 72:508-510.

6. Corner EM, Nitch CAR. The immediate and remote results of the high operation for varicocele. Br Med J 1906; 27:191-193.

7. Tait D. Contribution to the study of varicocele. Cal State J Med. 1904; 2:363-367.

8. Curling TB. Varicocele treated by pressure. Med Chir Trans. 1846; 29:259-268.

9. Osborn S. The treatment of varicocele by acu-pressure of spermatic vein. Br Med J. 1880; 1:52.

10. Duncan J. Clinical observations of the subcutaneous ligature of varix and varicocele. Br Med J. 1881; 2:37-38.

11. Robson AWM. Treatment of varicocele by excision. Br Med J. 1886; 27:389-390.

12. Ogston A. The operation for varicocele. Ann Surg. 1886; 4:120-123.

13. Noske HD, Weidmer W. Varicocele a historical perspective. World J Urol. 1999; 17: 151-157.

14. Keetly CB. The cure of varicocele. Ann Surg. 1888; 8: 205-207.

15. Turgut $H$. The effect of varicocelectomy on the pregnancy rate in patients with severe oligospermia. Niger J Clin Pract. 2020; 23:1744-1747.

16. Schlegel PN, Sigman M, Collura B, et al. Diagnosis and treatment of infertility in men: AUA/ASRM Guideline Part II. J Urol. 2021; 20:44-45.

17. Kimura M, Nagao K. Role of varicocele repair for male infertility in the era of assisted reproductive technologies. Reprod Med Biol. 2014; 13:185-192.

\section{Correspondence}

Nicola Zampieri, Prof., MD, PhD

nicola.zampieri@aovr.veneto.it

Pediatric Fertility Lab

Woman \& Child Hospital, Department of Surgery, Dentistry, Paediatrics and

Gynecology; Division of Pediatric Surgery, University of Verona, Italy

Piazzale Aristide Stefani 1, 37100 Verona (Italy) 